\title{
LEARNING APPLICATIONS FOR DISABLED PEOPLE
}

\author{
ATHANASIOS DRIGAS \\ Net Media Lab, Institute of Informatics \& Telecommunications, N.C.S.R. \\ 'Demokritos' (Greece) \\ Terma Patriarchou Grigoriou \& Neapoleos 27, Agia Paraskevi. 15310, \\ Athens, Greece \\ Phone number: +30-210-6503124 \\ Fax number: +30-210-6532910 \\ E-mail: dr@iit.demokritos.gr \\ DIMITRIS KOUREMENOS \\ Net Media Lab, Institute of Informatics \& Telecommunications, N.C.S.R. \\ 'Demokritos' (Greece) \\ Terma Patriarchou Grigoriou \& Neapoleos 27, Agia Paraskevi. 15310, \\ Athens, Greece \\ Phone number: - \\ Fax number: +30-210-6532910 \\ E-mail: dkourem@iit.demokritos.gr \\ JOHN VRETTAROS \\ Net Media Lab, Institute of Informatics \& Telecommunications, N.C.S.R. \\ 'Demokritos' (Greece) \\ Terma Patriarchou Grigoriou \& Neapoleos 27, Agia Paraskevi. 15310, \\ Athens, Greece \\ Phone number: +30-210-6503135 \\ Fax number: +30-210-6532910 \\ E-mail: jvr@iit.demokritos.gr
}




\title{
LEARNING APPLICATIONS FOR DISABLED PEOPLE
}

\begin{abstract}
This chapter presents e-learning practices and applications, which target people with visual and hearing disabilities. The first part discusses an elearning application, which targets visually impaired people while the second part presents an e-learning application for the teaching of the English language to deaf and hearing impaired people. The final part presents a study about the relationship of the deaf and hearing impaired with new technologies in Greece. The chapter stresses the importance of the thorough exploitation of ICTs together with e-learning technologies towards the effective improvement of educative methods for this target group. The objectives of this chapter are to support the distance and lifelong education and training of the target group, to guarantee their equal access to information, knowledge, education and employment and finally, to minimize the digital divide through the use of assistive technologies and contemporary, easily navigable and user-friendly e-learning environments.
\end{abstract}

\section{Keywords}

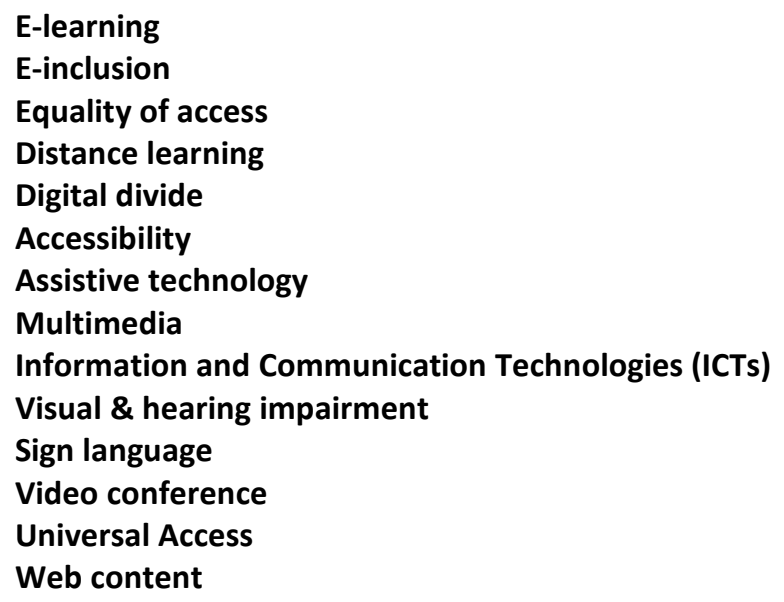




\section{E-LEARNING PRACTICES FOR VISUALLY IMPAIRED PEOPLE}

Promoting equality of access to Web content for disabled individuals is a primary goal of web designers nowadays. Keeping in mind that access to information and education is the most undeniable right of all people, it becomes clear that the adjustment of ICT services and the Internet content to the needs of disabled people and special target groups in general, especially in education issues is essential (Drigas, Vrettaros, Stavrou \& Kouremenos, 2004; Twining, 2007).

Very thorough international activity has been taking place, concerning the adjustment of the Internet to the special needs of the disabled people, through the use of special technological applications in the already existing communication mediums, with very important results. A large number of organizations and companies have been active in the area of preserving the rights of disabled people and have come up with gadgets that adjust the existing technological mediums to their needs. Web content can be available to all users and information can be found faster regardless of the user agent that is being used and regardless of their disability (Colace, DeSanto \& Vento, 2003; Graf \& List, 2005; King, 2003).

A significant number of methods contribute to the improvement of web content accessibility by various target groups of people such as people who have reading difficulties, people with cognitive and learning disabilities as well as hearing impaired people and people with mobility problems. Some of these methods include icons and videos depicting a person translating the text into the Sign language, enhancing internet access, multi web internet browsers, media access generators, sensus internet browsers, TTY-text phones, hearing aids, image phones for the deaf, special keyboards, joysticks, mouthsticks and sensors for those with mobility disabilities. All the aforementioned supportive technological equipment (assistive technology) stems from the continuous effort to familiarize the disabled in general, with the ICTs in order for them to become equal members of the information society (Angehrn \& Balakrishnan, 2004; Phipps, Sutherland \& Seale, 2002; Pilling, Barrett \& Floyd, 2004).

In visually impaired individuals' cases, there are numerous ways to tackle their disability. The most important ones are the auditory description of visual-multimedia information, which benefits the blind individuals, whereas for those individuals with sight disabilities there is the solution of the graphics enlargement with the use of special software. 
This section presents an e-learning environment that was developed and designed for the informing and education of blind and visually impaired individuals and their trainers (Geoffrey, Aimeur \& Gillet, 2002; Humar, Pusticek \& Bester, 2003). This e-learning environment provides the following possibilities to the people that it targets. Firstly, it incorporates technologies that cover the communicative needs and handicaps of the visually impaired. Moreover, it provides the opportunity to the users to make use of their alternative sensory routes such as hearing and touch for easier navigation and finally, it provides them with the opportunity to access web content that will initially inform them and in the long run ensure their equal access to information, knowledge, education and employment. The lifelong training-education of the trainer was considered a very crucial part of the project as it indirectly upgrades the education quality of the visually impaired.

Such supportive environments are mainly based on the principle of the knowledge and understanding of the handicaps of the visually impaired from a psychological point of view. It is essential to take this information into account in order to be able not only to smooth these handicaps, but also to enhance their other skills and finally, cover in full both their special personal as well as their communicative needs (Drigas \& Koukianakis, 2004; Drigas, Koukianakis \& Papagerasimou, 2006).

\section{System units presentation}

In psychology studies it is stated that individuals with visual impairments have their other senses (such as touch and hearing) upgraded, which in a way replace and fill in for the lack of or low eyesight. Unfortunately though, the use of one of the aforementioned senses alone is not adequate enough. It is essential that the visually impaired use a combination of their alternative sensory routes for better results. Hence, it becomes obvious that the elearning environment must provide such possibilities to the user. There were three main system units that were taken into account when designing this informative and educational e-system. The e-learning environment interface, the database structure and finally, the special tools that needed to be embedded in the system in order to achieve the main aim: the equality of access and the easy navigation of the visually impaired to web content. The discussed e-learning environment interface, contains technological and general information regarding the blind and the visually impaired and it is 
based on the multiple access interfaces, fulfilling the basic principles of "design for all" and "universal access".

Particular emphasis was given to the special access interfaces, which include audio navigation and the possibility of enlarging the text, in order to make the e-learning environment user friendly and easily navigable. The main aim was to ease the integration of the visually impaired to the ICTs and hence, to information, knowledge, education and employment. In addition, another important factor that was taken into account was the distance education of the disabilities specialists-trainers, as the upgrade of the specialists' knowledge has indirect effect on the upgrade of the training and education of the visually impaired.

Moreover, a database was created to be used by the trainers of the visually impaired, aiming at the scientific evaluation of the quality of the services that are provided to these people. This database constitutes a source of information as well as a database for the trainers of a disability centre, to which they can refer for the history and the progress of the special education of the visually impaired. More particularly, all the information that regards visually impaired people is inserted into the database. In addition, the therapeutic and educational work of the employees of the centre is inserted into the database together with the corresponding profile of the served population. The aim of this database was to upgrade the trainers' work in favour of the visually impaired.

Furthermore, special tools (assistive technology) were embedded in the system to support and assist the Internet access and navigation the visually impaired. Since visual access interfaces are of no use to blind people and are problematic for those with visual impairments, the need to create other special access interfaces arose, which would support the information flow through alternative sensory routes such as hearing and touch.

Regarding visually impaired people, common software-based assistive technology includes screen readers, which is a software program that reads the content of the screen aloud to a blind user. Screen readers can usually only read text that is printed, not painted, to the screen. Moreover, screen magnifiers are used, which is a software program that magnifies a portion of the screen, so that it can be more easily viewed by individuals with low vision and finally, speech synthesizers and voice/audio input software that operate in conjunction with graphical desktop browsers. Hardware assistive technology includes alternative keyboards, pointing devices and finally, 
Braille displays, which achieve the display of a large percentage of what is displayed on the screen.

In particular, Real Audio was used for the generation of audio messages, while for the incorporation of these messages within a web page, a special Real Player plug-in was used. In addition, the Macromedia Flash 5 Player is responsible for the enlargement of the graphics, while finally, JavaScript was used for the activation of certain keys on the keyboard that support and ease the navigation of the visually impaired user.

\section{Navigation techniques presentation}

In this section the e-learning environment is presented as well as its special access interfaces and its various navigation techniques and services. The elearning environments' entrance page guides the user as to the special tools that the user will need in order to use the environments' services. These are the Macromedia Flash Player and the Real Player. After this, the user enters the main interface of the environment.

Once the user has entered the main interface, an audio message can be heard and a moving image can be seen. This confirms the correct installation of the essential Macromedia Flash Player and Real Player tools. The main interface includes the e-learning environments' four navigation techniques. By choosing one of the four navigation techniques, namely, Audio based Navigation, Graphics based Navigation, Braille Terminal or Screen Reader Navigation and Common Citizens Navigation the corresponding interface will appear. For the visually impaired individual there is an audio message that welcomes and instigates the user to press one of the 1,2,3,4 keys in order to be navigated to one of the four aforementioned interfaces.

Audio based navigation

The visually impaired are navigated through audio messages (Real Audio) to audio information only. This means that the installation of the Real Player tool is essential for the navigation of the visually impaired user. The navigation through the pages is realized by pressing the keys according to the instigation of the corresponding audio message. The keys that are used are "enter" to return to the main interface, "space" for returning to previous pages and the numerical ones "1-9" for the navigation through the pages. Once the interface is loaded, an audio welcome and navigation message is 
heard. The activation of the keys was realized with JavaScript, while the audio navigation was realized with the generation of real audio messages and their incorporation in a page through the special Real Player plug-in.

The thematic units are exactly the same as the ones in the common citizens interface, except for the multimedia ones (video, video on demand and video conference) for the obvious reason that they cannot be used by the visually impaired. The only multimedia unit that is present here is the audio books.

Graphics based navigation

The structure of this interface is exactly the same as in the common interface, except that through the installation of a special Flash Player plugin, the user may enlarge both the graphics and the text. The enlargement process, which is given sonically by navigating the user to the corresponding interface, is realized by right clicking the mouse and choosing zoom in. This interface's possibility is due to the special design of the web pages using the Macromedia Flash 5 tool.

Braille terminal or screen reader

The information that the user finds in this interface is the same as the information provided in the Common and Graphic Enlargement Interfaces, the difference lying in the fact that it is presented in plain text format with a large font in order to be able to easily use either a Braille Keyboard or a Screen Reader. This is because the graphics impede the use of the aforementioned tools and hence, it is essential to have a simple environment. In addition, this interface contains all the information of the Common Interface and has been designed in such a way, in order to collaborate with a Hellenic Screen Reader and a Braille Terminal, which serve the educational needs of the visually impaired by accessing the network environment.

Common citizens navigation

In this interface, the non-disabled interested users may navigate through the information of the e-learning environment through columns of links as happens in a normal web portal. In particular, this interface is mainly addressed to the trainers as well as the family members of the visually impaired users.

This page consists of four units namely, Technology, Information, Organizations and Multimedia. The unit "Technology" contains information 
about technological supportive tools for people with visual and mobility impairments such as Braille terminals, and screen readers.

The unit "Information" contains useful information such as books about disabled people according to the disability, magazines and links to Hellenic libraries where these magazines can be found, hyperlinks of the most important Hellenic and foreign web sites that engage in disabilities issues and finally, information about causes of child eyesight loss.

The unit "Organizations" contains information about all the institutions and organizations related with disabilities in Greece. Finally, the unit "Multimedia" contains educational and recreational material for both the disabled people as well as their trainers such as digital videos of educational activities taking place at disability centers according to the thematic of the activity as well as links to these videos, excerpts from Audio books that are available in Real Audio and Greek and foreign links to radio stations on the Internet and also to music web sites. Finally, this interface provides two very useful services. The first is Video on demand using the IPTV Viewer 3.0 and also audio and video conference services.

\section{ENGLISH E-LEARNING PRACTICES FOR DEAF PEOPLE}

Despite the vast and rapid evolution of information and communication services and products, only a small percentage of these are used within the linguistic training circle and even a smaller percentage are used to support the linguistic training of impaired people and especially of deaf and hearing impaired people. The general idea is that the majority of the Information and Communication Technologies (ICTs) and services target the common user, and exclude handicapped people and other sensitive community groups. This fact provokes and creates a phenomenon more commonly known as 'digital divide', or in other words, the exact opposite of e-inclusion, which is supported internationally by several policies and organized actions (Molla, and Al-Jaghoub, 2007).

This section presents an e-learning environment that aims at the promotion of the English language as a second language for deaf and hearing impaired people whose mother tongue is the sign language. Towards this aim, a special pedagogic methodology of distant linguistic training was designed and used together with innovative educational e-content, suitably adapted to the needs of the deaf and hearing impaired. The whole process includes 
audits and evaluation of the linguistic skills of the e-students. The educational e-content was designed to be divided into different levels according to the knowledge level of the students. The system has been designed to evaluate the student and set the pedagogic material at the corresponding level using an intelligent taxonomy system. Particular emphasis was given to the quality and innovation of the educational material where new animation and digital video technologies were extensively used (Tavangarian, Leypold, Nölting, Röser, and Voigt, 2004; Rosenberg, 2000; Drigas, and Koukianakis, 2006).

An important element of the task was the promotion of equality of the deaf and hearing impaired people through their participation in the European Community. Nowadays, the English Language as a second language constitutes an important asset in the professional field, for all individuals.

The Greek sign language (GSL) is a natural visual language used by the members of the Greek Deaf Community, which counts several thousands of native and non-native signers (Antzakas and Woll, 2002; Lampropoulou, 1992). There is also a large number of hearing non-native signers of GSL, mainly students of GSL and families of deaf people (Lampropoulou, 1992; Bellugi and Fischer, 1972). The recent increase of mainstreamed deaf students in education, as well as the population of deaf students scattered in other institutions, minor town units for the deaf and private tuition may well double the total number of secondary and potential Sign language users (Kyle and Woll, 1985; Efthimiou and Katsoyannou, 2001; Wilcox, 2003).

\section{Project steps}

The projects' basic objective is to support the equality of access and the real participation in professional training for deaf people (Phipps, Sutherland and Seale, 2002). Moreover, the main aim is the promotion of the English language as a second language for the deaf and hearing impaired through distant linguistic training using innovative educational material (e-content) suitably adapted to their needs. The steps that were followed for the realization of the project were as follows:

- Design and development of an e-learning environment for the deaf and hearing impaired, adapted to their special needs through the use of sign language.

- Design and development of electronic informative and adaptive material (e-content) for the deaf and hearing impaired people on the 
Web. This informative material includes text and sign language videos (multimedia) and aims at the teaching of the English language.

- Design and use of innovative e-learning methods for linguistic training with self-paced learning. Processes of synchronous learning and collaborative methods of asynchronous self-paced learning were used (Moore, 1989; Moore and Kearsley, 1995; Naeve, Lytras, Nejdl, Harding and Balacheff, 2006; Lytras, 2007; Lytras and Sicilia, 2005).

- Design and operation of an application for lifelong and distance learning of the English language. In this application, all the aforementioned actions and developments were designed and coordinated so that the desired training outcome is available to the deaf community for implementation and evaluation that will lead to the final improvements of the central and the subsidiary design and developments.

\section{The e-learning application}

The e-learning application has been designed using both asynchronous services for the delivery of the educational material as well as asynchronous services of communication and collaboration, in an effort to surpass the barriers that are related with the time and the place of training but also to satisfy the needs of deaf and hearing impaired students with a variety of possibilities of equipment and communication.

Moreover, the model of the visual classroom has been designed using video conference services through images, with the possibility of realization of cooperative real-time activities (whiteboard, application sharing, file sharing).

Apart from the designed visual classroom model, the model of supported self-paced learning is also in use. In addition, the educated person is simultaneously able to use the course and to intervene in the flow and its structure. In this designed model the strategy is learner centered.

The designed services that are provided by the e-learning environment are categorized into the following axes:

- Visual order: line of courses in real time with the possibility of interaction through the Internet.

- Self-instruction: access (search and recovery) to training and informative material for various cognitive and more general subjects that interest teachers. 
- Collaborative learning: communication and attendance in thematic circles of discussions and development of collaborative activities;

- Files: the instructor can upload files to the server. Students do not have access to these files unless the instructor links them to another part of the site. A file can be text documents, sound files, spreadsheets etc.

- Grades: there is the capability of grading tests, quizzes and projects that students have undertaken.

- Questionnaire: the questionnaire module allows users to complete online feedback style forms using a variety of user input methods.

- Scorm/AICC: the Scorm activity allows the inclusion of a Scorm lesson within the e-learning environment. Scorm is a common system for putting together online learning experiences, and there are many packages that can export activities in Scorm format.

- Survey: instructors can add pre-built surveys to the class. These are typically used for online, distance learning courses.

- Wiki: instructors can add a Wiki to their class. A wiki is similar to a blog, the difference being that everyone can contribute, edit and comment so the content can be built very quickly.

- RSS Feeds: the e-learning platform supports outgoing RSS feeds. This option needs to be enabled by the administrator. Once enabled, RSS is available in the forum and glossary modules. RSS is a technology where visitors to a web site can choose to have the web site send new postings to an RSS aggregator. RSS allows a user to build a custom news service. When users subscribe to a RSS-enabled page, they will get new postings from forums and/or new entries in glossaries without having to visit the e-learning site every day.

\section{The e-content}

The purpose of the discussed e-learning environment could be summarized as teaching - tutoring deaf students in order to meet the ESOL level 1 and level 2 standards (developed by the Department for Education and Skills (DfES) and the Basic Skills Agency (BSA)). Each of these two levels consists of the same five sections. Their semantic differential is located on the language skills acquisition each level defines as necessary - appropriate. An abstract e-learning schema of the final system is the following: The learning process consists of three stages. Each individual deaf student must successfully complete each stage in order to proceed to the next. Also, a 
fundamental assumption is that there exists a logical/obvious priority list containing all sections in a certain ascending order.

The section priority list begins with the letter recognition and alphabetical order, then follows the spelling and vocabulary, before the grammar and sentence structure. The section priority list ends with the reading and finally, with the writing. The e-learning process is presented in length next together with the analysis of some key issues.

The e-learning process begins with the acquisition of the necessary language skills for each individual section. Per section questions or questionnaires are interchanged with corresponding instruction/lesson sessions. This process ends only after the deaf student completes all sections successfully. If an accurate assessment (according to statistical thresholds) of the student's language level cannot be reached, more questions are employed.

The e-learning process continues with the acquisition of language skills relevant to each section and to the section(s) lying above it. The deaf student is provided with questions relevant to a certain section and simultaneously relevant to all the corresponding prerequisite sections (of the section under consideration). Two issues are of vital importance; answers could be simultaneously right according to some sections and wrong according to others and also the part of an answer relating to a specific section could be partially right. Moreover, the question itself exhibits a different degree of relevance/weight with respect to each individual section. Finally, the elearning process concludes with the overall verification - evaluation of the student's exact language level. Questions at this stage are more complex, combining various arbitrary sections, which are chosen randomly instead of being selected in some formal way.

\section{E-LEARNING PRACTICES FOR ICT'S AND DEAF PEOPLE}

Individuals with hearing disabilities are exposed either as persons, or as organized communities in communicational problems, which can be reduced or enhanced due to the brainstorming of information (Kersting, 1997). Due to their impairment the deaf cannot manage the communication mediums in their whole, resulting to their social relegation, because knowledge and access to information is very important nowadays for the social-economical status of each person (Akach and Woodford, 2000).

The Internet and its services reduce substantially the differences between 
hearing people and hard of hearing people, because in this case, information is primarily offered visually and less sonically. A hard of hearing person can have access to information of the same depth and plurality as a hearing person. (Sanger, 2006).

The kind of information offered through the Internet, spreads from text, to image, to audio documents and complex video. The information offered is available in different media presentation forms, as a result of the technological convergence between the content of older communicational mediums (text, image, audio, and video). For the people with hearing impairment that is the step for complete access to the Information Society (Bozinis and Iakovou, 2005; Caldow, 2004).

Numerous websites have appeared lately, which are managed by people with hearing impairment. These websites concern deaf people and their environment, and their content varies, including discussions, press reports, links, social services, communication capabilities, instructions for TV shows with subtitles, researches and scientific papers. One of the most important features of the Internet is interactivity. In addition to the classic communication mediums, the user can participate in the information offering, its updating and its handling, so that the user emerges as a producer and as an information dealer.

The deaf constitute the primary target user group who need e-learning tools and educational material for the e-services and new technologies sector (Riley and Riley, 2003; Drigas, Vrettaros, Kouremenos and Stavrou, 2004; Lytras, 2007; Lytras and Sicilia, 2005). Till very recently e-learning systems were unavailable to students with hearing impairment. However, the userfriendly multimedia-based, communication and information services of the Internet can be used as a standard electronic platform to support primarily the main procedures of distance, lifelong and continuous training for the deaf (Drigas, Vrettaros and Kouremenos, 2004; Bose, 2004). The communication and information services are adjusted to their special needs through the use of Sign language, and this is a certain method towards the general improvement of the educational and training services provided for the deaf people (Hughes, Hudgins and MacDougall, 2004; Henderson, Grinter and Starner, 2005).

The main objective is to support the equal rights of deaf people for their access and real participation in the professional training (Drigas, Vrettaros, Kouremenos and Stavrou, 2004). The final aim is the creation of a passage 
for these individuals into the new professional fields via their training with specialized knowledge and skills in the use of the continuously developing e-services. Specifically, this knowledge and experience will constitute a supply for their lifelong training and education. An important blossoming in the work market has been observed in e-services and new places of work are continuously created.

The main research question that was aimed to be clarified though the present research, based on an empirical approach, was how people with deaf impairment can or are willing to manage concepts and capabilities through the Internet, such as e-learning, e-commerce and e-government (Lytras, 2007). Additionally, the relationship between deaf people and the computer is explored, as well as the motives and the character of this relationship.

\section{Assumptions and research questions}

The assumptions that are examined refer to centric theoretic concepts, such as integration, information, Internet use and its extensions (communication). Hence, the following assumptions were structured accompanied by their reasoning, which were set under examination through the use of a questionnaire.

1. Deaf people have sufficiently gained skills for the use of the computer and the Internet.

2. Deaf people don't have the lingual skills for using the capabilities offered through the Internet.

3. Deaf people can be informed through the Internet about various subjects.

4. Deaf people with access to the Internet mostly use it as an information source.

5. Sign Language consists the most suitable way for facilitating deaf people with the use of the Internet

6. Deaf people have minimum knowledge of the capabilities and applications of e-learning, e-commerce and e-government

7. Deaf people show special interest in future training on the applications of e-learning, e-commerce and e-government

8. Deaf people believe that the use of new technologies is highly important for their professional integration and improvement.

\section{Methodological Approach}

The online questionnaire was filled in by a representative sample of 53 deaf 
people anonymously, who are members of two of the largest deaf organizations in Athens as well as Internet users. It was highlighted that the questions concern only deaf people and not hard of hearing people, in order to define the respondent group from the beginning. For the examination of the assumptions and the research questions, the written questionnaire method was designated, which is considered more appropriate for the recording of attitudes and opinions of people. The questionnaire is a well structured tool of empirical social research, which consists of close and open ended questions. The questionnaire was presented and filled in at an Internet website and could alternatively be sent by email. The method of the online questionnaire was chosen based on the purposes of the research approach, which is related with the use of the Internet and therefore was directly referred to the target group (deaf users of the Internet).

The advantages of the online survey have to do on the one hand, with the low cost and on the other, with the capability of directly processing the research data. A disadvantage is the fact that the deaf people consist only a minor percentage of the Greek population, from which comparably only a small part has access to Internet services.

From a database comprising fifty questions, fourteen simple questions, which were considered appropriate, were chosen in collaboration with a group of experts as far as their lingual structure and their notional content were concerned. In two successive pilot applications on deaf people with similar psychometric elements with the population we are concerned with, improvements were made on certain questions depending on their difficulty and understanding level.

An online panel site tool was developed, which consists of a simple series of modules in the application for online research for the conduction of the online survey. The data processing was simplified through the aforementioned online tool, because it comprised the largest part of this process. Moreover, with the help of the online tool, the initial data where enhanced in the SPSS statistic analysis program for further processing.

The younger deaf people of the sample (16-25 years old) took part in the online survey. This fact enforces the position, that the age is a variable of great importance regarding the relationship of the deaf people with the Internet. $56 \%$ of the sample has attended only a school for the deaf, but a large percentage of the sample has education of a higher level. The ascertainment that the largest percentage of the deaf people that took part in 
the survey are unemployed, is explained, partly due to their young age, but is also a clear indication of the difficulties that the deaf people confront in order to gain access to employment.

\section{Assumptions analysis and results}

The assumptions and research questions must sufficiently satisfy the problematical of the present research, which is the educational needs of the deaf people regarding the Internet and its applications.

1. Deaf people have sufficiently gained the skills for the use of the computer and the Internet, but in the case of extended and productive use of the Internet, they present medium to low ability.

2. Deaf people don't have the lingual skills to use the offered Internet capabilities. A large percentage of the sample (34\%) doesn't speak foreign languages, a fact which is an obstacle for their relationship with the new technologies.

3. Deaf people can be informed through the Internet about various subjects. From the online survey it was deduced that deaf people use the Internet services typically. The observation that the Internet is chosen as a means for entertainment, probably means that the Internet is considered as more attractive compared with television or the written press, where there is no capability of subject presentation neither in the sign language nor with the use of multimedia.

4. Deaf people with access to the Internet mostly use it as an information source. The results from the survey enhance this assumption. Over $80 \%$ of the deaf people of the sample believe that they are more efficiently informed and that they communicate easier and faster with the use of the Internet.

5. Sign Language consists the most suitable way for facilitating deaf people with the use of the Internet. The results from the survey confirm that the combination of Sign Language and multimedia is a very important factor and one that will probably contribute to a more massive use of the Internet by deaf people.

6. Deaf people have minimum knowledge of the capabilities and the applications of e-learning, e-commerce and e-government. From the conducted survey, one can confirm that the difficulties that the people have accessing and using the Internet, are the main factors why deaf people can't understand and therefore participate in e-learning, e- 
commerce, or e-government activities.

7. Deaf people show special interest in future training on the applications of e-learning, e-commerce and e-government. Despite the fact that deaf people don't have the knowledge or haven't be trained in order to participate in e-learning, e-commerce or e-government activities, they are willing to be trained in the use of these technological capabilities and their applications in common economical, social and professional aspects.

8. Deaf people believe that the use of new technologies is highly important for their professional integration and improvement. Regarding the professional evolution of the deaf people that use the Internet, $70 \%$ of the sample believes that these technologies will help them efficiently.

The presented survey aimed to make clear the deaf people's place in society regarding the use of the Internet and the new technologies and whether these new technologies can comprise a means for their integration in the social, economical and professional life.

Undoubtedly, the informing and communication of the deaf people has improved significantly with the use of the Internet. Better communication means greater participation in social life, because through the communication with other people, one can participate in social changes more easily. On the other hand, better informing means understanding and awareness of the surrounding air, ideas, values and the orientation of the society. The extensions and the applications of the Internet, which offer an open communicational frame of interaction, allow the deaf people's clean contact with all the possible receivers, whether they are deaf or not, putting a definitive end to deaf people's social exclusion.

\section{CONCLUSIONS}

The focus of this chapter was the visually and hearing impaired people with respect to education issues through e-learning applications and the relationship of deaf people with the Internet and the new technologies in Greece. Throughout the chapter, emphasis was given to the major importance that the Internet and ICTs play towards the e-inclusion of disabled people and their equal access to information, knowledge, education and employment. Of course, it must be mentioned that the whole approach 
towards the aforementioned applications was based on the fact that the ICTs constitute a very powerful tool towards the decrease of the problems that the disabled people face and that under no circumstances do they conceal them. The first part of this chapter dealt with an e-learning environment for people with sight disabilities, which incorporated special assistive technology, adapted to their needs, in order to make navigation feasible for the visually impaired. The basic objective of this environment was to include and support the participation of the visually impaired in e-learning activities, which will contribute to their lifelong education and training and render them equal members of the so-called information society.

The second part of this chapter presented an e-learning environment for the teaching of the English language to deaf and hearing impaired people whose mother tongue is the Sign Language. Special pedagogical methods for distant lingual training were embedded in the e-environment together with high quality e-content in video format (sign language videos) for the deaf and hearing impaired. Lastly, assessment and evaluation methods and tests were used within the e-learning environment in order for the instructors to be able to monitor the skills of the hearing impaired students.

Finally, the third part of this chapter dealt with a study about the relationship of the deaf and hearing impaired with new technologies in Greece. The study was based on an online questionnaire, which was filled in by deaf people. The aim of this study was to fully understand the needs of the hearing impaired with respect to new technologies and how these can contribute to their e-inclusion and their lifelong training. The results of the study indicate that the Internet offers a lot of potential regarding the deaf and the hearing impaired and that deaf and hearing impaired people use and are willing to exploit the Internet further. This can be achieved provided that special environments covering their informative and communicative needs are developed with the use of multimedia tools (digital video) and their mother tongue (sign language). Through the Internet disabled people can interact with other people, they can access useful information, they can learn and most importantly, they can feel active members not only of the Internet world but of the society in general. 


\section{References}

Akach, P. \& Woodford, D. (2000). Deafness: A Guide for Parents, Teachers and Community Workers. UNESCO.

Angehrn, N.T. \& Balakrishnan, R. (2004). Integrating Context in E-learning Systems Design. Proceedings of the IEEE International Conference on Advanced Learning Technologies, 355-359.

Antzakas, K., \& Woll, B. (2002). Head Movements and Negation in Greek Sign Language. Gesture and Sign Language in Human-Computer Interaction (Springer Lecture Notes In Computer Science). 2298(2002), 193-196.

Bellugi, U., \& Fischer, S. (1972). A Comparison of Sign Language and Spoken Language. Cognition 1, 173-200.

Bose, R. (2004). Information Technologies for Education and Training in E-government. Proceedings of International Conference on Information Technology: Coding and Computing. 2, 203-207.

Bozinis, A.I. \& Iakovou E. (2005). Electronic Democratic Governance: Problems, Challenges, and Best Practices. Journal of Information Technology Impact. 5(2), 73-80.

Caldow, J. (2004). E-democracy: Putting Down Global Roots, Institute for Electronic Government, IBM.

Colace, F., DeSanto, M. \& Vento. M. (2003). Evaluating Online Learning Platforms: A Case Study. Proceedings of 36th Hawaii International Conference on System Sciences, IEEE Press.

Drigas, A.S. \& Koukianakis L.G. (2004). A Modular Environment for E-learning and Epsychology Applications. WSEAS Transactions on Information Science and Application. 6(3), 2062-2067.

Drigas, A.S., \& Koukianakis, L.G. (2006). An Open Distance Learning E-System to Support SMEs E-Enterprising. In Proceedings of the 5th WSEAS International Conference on Artificial Intelligence, Knowledge Engineering and Databases. 297-302.

Drigas, A.S., Koukianakis, L.G. \& Papagerasimou, Y.P. (2006). A Web Based E-Learning and E-Psychology Modular Environment. International Conference on Next Generation Web Services Practices. 168-174.

Drigas, A.S., Vrettaros, J. \& Kouremenos, D. (2004). Teleeducation and E-learning Services for Teaching English as a Second Language to Deaf People, whose First Language is the Sign Language. WSEAS Transactions on Information Science and Applications. 1(3), 834-842.

Drigas, A.S., Vrettaros, J., Kouremenos, D. \& Stavrou, L. (2004). E-learning Environment for Deaf People in the E-commerce and New Technologies Sector. WSEAS Transactions on Information Science and Applications. 1(5), 1189-1196. 
Efthimiou, E., \& Katsoyannou, M. (2001). Research Issues on GSL: A Study of Vocabulary and Lexicon Creation. Studies in Greek Linguistics. 2, 42-50.

Geoffroy, F., Aimeur E. \& Gillet, D. (2002). A Virtual Assistant for Web-based Training in Engineering Education. Intelligent Tutoring Systems, Springer Lecture Notes in Computer Science, 2363(2002), 9-24.

Graf, S. \& List, B. (2005). An Evaluation of Open Source E-learning Platforms Stressing Adaptation Issues. Fifth IEEE International Conference on Advanced Learning Technologies, 163-165.

Henderson, V., Grinter, R.E. \& Starner, T. (2005). Electronic Communication by Deaf Teenagers. Technical Report, Georgia Institute of Technology.

Hughes, G., Hudgins, B. \& MacDougall J. (2004). Remote Sign Language Interpretation Using the Internet. Proceedings of Second Annual Conference on Communication Networks and Services Research. 345-350.

Humar, I., Pustisek, M. \& Bester, J. (2003). Developing Dynamic Educational Material with Integrated Mathematical Notation for Web-based E-learning System. 33rd ASEE/IEEE Frontiers in Education Conference, 1, T3F-19-T3F-24.

Kersting, S. (1997). Balancing Between Deaf and Hearing Worlds: Reflections of Mainstreamed College Students on Relationships and Social Interaction. Journal of Deaf Studies and Deaf Education, 2(4), 252-263.

King, N.J. (2003). Website Access for Customers with Disabilities: Can We Get There From Here?. UCLA Journal of Law and Technology, 6.

Kyle, J. G., \& Woll, B. (1985). Sign Language: The Study of Deaf People and Their Language, Cambridge University Press.

Lampropoulou, V. (1992). Meeting the Needs of Deaf Children in Greece. A Systematic Approach. Journal of the British Association of the Teachers of the Deaf. 16(2), 33-34.

Lampropoulou, V. (1992). The Socioeconomic Status of Deaf People in Greece. Journal of the British Association of the Teachers of the Deaf. 16(4), 90-96.

Lytras, M.D. (2007). Teaching in the Knowledge Society: An Art of Passion. International Journal of Teaching and Case Studies. 1(1/2), 1-9.

Lytras, M.D. (2007). The Semantic Electronic Government: Knowledge Management for Citizen Relationship and New Assessment Scenarios. Electronic Government, an International Journal, 3(1), 5-17.

Lytras, M.D. \& Sicilia, M.A. (2005). The Knowledge Society: A Manifesto for Knowledge and Learning. International Journal of Knowledge and Learning. 1(1/2), 1-11.

Molla, A. \& Al-Jaghoub, S. (2007). Evaluating Digital Inclusion Projects: A Livelihood Approach. International Journal of Knowledge and Learning. 3(6), 592-611.

Moore, M.G. (1989). Three Types of Interaction. The American Journal of Distance 
Education. 3(2), 1-6.

Moore, M.G., \& Kearsley, G. (1995). Distance Education: A Systems View. Wadsworth Publishing.

Naeve A., Lytras M., Nejdl W, Harding J., \& Balacheff N. (2006). Advances of Semantic Web for E-learning: Expanding learning frontiers. British Journal of Educational Technology, 37(3), 321-330.

Phipps, L., Sutherland, A., \& Seale, J. (2002). Access All Areas: Disability, Technologies and Learning. York: JISC.

Pilling, D., Barrett, P. \& Floyd, M. (2004). Disabled People and the Internet Experiences, Barriers and Opportunities. York: The Joseph Rowntree Foundation.

Riley, T.B. \& Riley, C.G. (2003). E-governance to E-democracy: Examining the Evolution. International Tracking Survey Report, No. 5.

Rosenberg, M.J. (2000). E-Learning: Strategies for Delivering Knowledge in the Digital Age. McGraw-Hill.

Sanger, L.M. (2006). The Future of Free Information, Digital Universe Journal, 2006(1).

Tavangarian, D., Leypold, M., Nölting K., Röser M., \& Voigt D. (2004). Is E-Learning the Solution for Individual Learning? Electronic Journal of E-Learning. 2(2), 273-280.

Twining, P. (2007). Discussing ICT, Aspirations and Targets for Education: International Perspectives. International Journal of Knowledge and Learning. 3(2/3), 154-170.

Wilcox, S. (2003). The Multimedia Dictionary of American Sign Language. Learning Lessons about Language, Technology, and Business. Sign Language Studies. 3(4), 379-392. 